\title{
Measuring the Accessibility of Public Transport: A Critical Comparison Between Methods in Helsinki
}

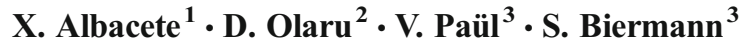

Received: 19 March 2015 / Accepted: 5 November 2015 /

Published online: 3 December 2015

C) The Author(s) 2015. This article is published with open access at Springerlink.com

\begin{abstract}
This research compares two location-based methods of evaluating public transport accessibility and applies them in Helsinki. After discussing a series of methodological aspects, the authors calculate the Structural Accessibility Layer (SAL) public transport indicator and the Public Transport and Walking Accessibility Index (PTWAI) for a grid with 8,325 zones, comparable in size to the smallest census unit. Both methods are operational for urban planners and policy makers interested in a relatively straightforward way of quantifying the accessibility of sustainable transport modes such as public transport. The results display similar accessibility patterns when moving from larger to smaller isochrones (60 to $38 \mathrm{~min}$ ). However, the findings are inconclusive between SAL and PTWAI: SAL (38 min) displays good accessibility by public transport (more than $94 \%$ of the population living within two-thirds of the metropolitan area has very high and high access to public transport), but PTWAI indicates that $35 \%$ of the population, primarily households with children (43\%), experience low and very low access. The contrasting results are mainly due to the derivation of the two indicators and have considerable implications for policy making. The findings of this research imply that PTWAI is preferable to planning assessments regarding public transport, given its relatively richer content. However, for multi-mode-based accessibility categorization, SAL appears more appropriate. It is the analyst's role to understand the objective and contents of each index and choose the tool fit for their purpose. Then, a judgement should be made on the trade-off between the
\end{abstract}

X. Albacete

xavier.albacete@uef.fi

1 Department of Environmental Sciences, Research Group of Environmental Informatics, University of Eastern Finland, P.O. Box 1627, FI-70211 Kuopio, Finland

2 Business School, Management and Organisations, University of Western Australia, P.O. Box M261, 6009 Perth, WA, Australia

3 School of Earth and Environment, Planning and Transport Research Centre (PATREC), University of Western Australia, P.O. Box M004, 6009 Perth, WA, Australia 
detail of the measures and results and the computational burden. Given the sensitivity of the models to various input parameters and assumptions, crossvalidation and replication are key for ascertaining the credibility and usefulness of the models.

Keywords Accessibility index · Public transportation $\cdot$ Location-based measure

\section{Introduction}

Promoting sustainable transport modes in urban areas (namely, walking, cycling and public transport) has become a primary objective in urban policy making. Projects such URBAN-LEDS (ICLEI 2014) reflect global attention to this issue. As a consequence of such interest, recent years have witnessed an explosion in the number of methods developed for measuring accessibility, especially by sustainable transport modes (Bhat et al. 2002; Kwan et al. 2003; Murray and Wu 2003; Halden et al. 2005; Páez et al. 2012). Measuring accessibility, in turn provides a benchmark for the evaluation of future scenarios for urban populations (see Wegener and Fürst 1999). For example, Handy and Niemeier (1997) list seven methods for measuring accessibility, Geurs and Ritsema van Eck (2001) list 23 and Halden et al. (2005) present 19. However, Mavoa et al. (2012) suggest that there is no effective comparison among these methods. Similarly, Curl et al. (2011) point out the lack of performance-based assessments indicating the actual usability of these various methods. Previous research includes limited examples of comparisons between methods (e.g., qualitative reviews, (Lei and Church 2010); differences between normative and positive implementations of accessibility indicators, (Páez et al. 2012); the effect of geographical context and scale, (Kwan 1998; Kim and Kwan 2003), but to our knowledge, no research investigated specific quantitative comparisons of different methods and measurements.

This article compares the Structural Accessibility Layer (SAL - Silva 2008) and the Public Transit and Walking Accessibility Index (PTWAI - Mavoa et al. 2012) methods for measuring accessibility. This is done by using a case study of the Helsinki metropolitan area, chosen because of data availability and personal knowledge of the area. This article is of interest for scholars, as it will help clarify the impact of methodologies on evaluating public transport accessibility, assisting policy makers gain a better understanding of the strengths and weaknesses of each method in terms of their empirical use for urban planning and management. Finally, this research compares methods in Helsinki, where no previous comparison has been undertaken.

The remainder of this article is organized as follows: First, it reviews the accessibility measures and their components (Section 2). Second, it examines the two location-based methods of interest (Section 3) and their adaptation to the context of Helsinki (Section 4). Finally, it discusses the suitability of the methods for urban planners and policy makers to quantify accessibility of sustainable transport modes (Section 5), as well as the contributions of the case study results to the scientific debate involving use of accessibility methods (Section 6). 


\section{Reviewing Accessibility Measures}

Researchers have defined accessibility variously as "the potential of opportunities for interaction" (Hansen 1959, p.2), "the inherent characteristic (or advantage) of a place with respect to overcoming some form of spatially operating source of friction (for example, time and/or distance)" (Ingram 1971, p.101) and "the extent to which landuse and transport systems enable (groups of) individuals to reach activities or destinations by means of a (combination of) transport mode (s)" (Geurs and van Wee 2004, p.128). The common element in these definitions is the ability "to reach", which indicates that, basically, accessibility means people's ability to get to or arrive at destinations, services or opportunities by means of a movement or transport.

All accessibility measurements assess the connections between land-use and transport in some form. Thus, accessibility measurement has been useful for evaluating how this interrelation affects usage of travel modes, including sustainable transport such as public transit, cycling, and walking (Handy 2002). Scholarly reviews classify accessibility measurements and their components in several ways (van Wee et al. 2001; Halden et al. 2000, 2005).

Kwan et al. (2003) indicate that the geographical access "can be conceived as an attribute of either location (place accessibility) or individuals (personal accessibility)" (p. 130), and can be evaluated at a global and local scale, embedding time or otherwise.

Geurs and van Wee (2004) summarise four types of accessibility measures. First, infrastructure-based accessibility or proximity measures focus on times, congestion and operating speed in the transport (road or rail) network (i.e., generalised cost to reach activities). Second, utility-based accessibility indicators are measured at the individual level, assuming that the users aim to maximize the benefit of their travel after accounting for the cost (Ben-Akiva and Lerman 1985). Therefore, they account for both user and transport modal characteristics. Third, person-based measures focus on the availability of the activities for a person within a given time, focusing on the individual freedom to participate in activities under given conditions of time and transport (see time-space prisms, Hägerstrand 1970; Kim and Kwan 2003, or activity/action spaces, Axhausen 2007). Finally, location-based (also known as zonal-level) accessibility measures account for the spatial distribution of opportunities and the demand for them.

Páez et al. (2012) provide an alternative view of the accessibility measures, particularly how they are implemented, to address positive and normative analysis needs. They refer to normative (prescriptive) measures reflecting how far it is reasonable to travel or how "it ought to be", and to positive (descriptive) measures, based on experienced traveling conditions. Regardless of the perspective, there are numerous ways to measure accessibility, however all combine two components of accessibility: cost of reaching destinations and the quality and quantity of opportunities available at those locations.

According to Curl et al. (2011), location-based accessibility measures are the most commonly used, because they are easier to assess and communicate and are less data hungry; thus, researchers typically deem them appropriate for informing and monitoring the achievement of transport planning goals. Moreover, the other measures have some limitations that are absent in location-based measures: infrastructure-based measures are not sufficient for analysing the spatial distribution of opportunities, and utility-based and person-based accessibility measures are costly in terms of data requirements and difficult to interpret. 
Location-based accessibility measures can be further divided into five types of measures (Geurs and Ritsema van Eck 2001; Tillema et al. 2003; Geurs and van Wee 2004): (1) distance approaches based on direct distance measurement (e.g., Bertolini et al. 2005; Curtis and Scheurer 2010; Ingram 1971); (2) contour measures (Breheny 1978) based on opportunities that can be accessed within a certain travel time, distance or cost (e.g., O'Sullivan et al. 2000); (3) potential accessibility measures (Koenig 1980), scaled by a deterrence function (Hansen 1959) e.g., Gutierrez and Gomez 1999; Kawabata and Shen 2006); (4) measures based on balancing factors of spatial interaction models (Wilson 1967, 1971; Williams and Fotheringham 1984; Fotheringham and O'Kelly 1989; and (5) measures derived from time-space geography based on Hägerstrand's (1970) time-space prisms (classified as person-based measure in Geurs and van Wee 2004) (e.g.,; Miller 1991; Lovett et al. 2002).

In the current research, we follow Geurs and van Wee's (2004) classification, because they clearly break down the various components of accessibility (Table 1) and use them to classify various methods of determining accessibility.

The transport component is based on the supply of infrastructure, demand for passenger and freight transport, and characteristics of the resulting infrastructure use; it is measured in terms of time, cost, effort and distance decay functions. The land-use component is based on the spatial distribution of the supplied destinations/opportunities and of the demand of activities and their characteristics. The interaction between the supplied destinations and the demand forms the basis of the competition measurements.

The scale of the area considered in the competition measures may have a strong effect on the final results (Goudie 2002; Páez and Scott 2005). The most commonly recommended action is to have as much disaggregated spatial data as possible so that the results are as detailed as possible (Handy and Niemeier 1997).

The temporal component pertains to the "reachability" of activities at different times of day, weeks, seasons or years, and the times at which people participate in specific activities.

Finally, the individual component is based on the needs, abilities and opportunities of the citizens of interest (Vlek and Steg 1996). In general, the individual component of accessibility is incorporated into accessibility measures by stratifying the population according to a selection of relevant characteristics. The more characteristics are incorporated in the measure, the more precise the outcome of actual accessibility; however, more characteristics require more data, and interpretation is more difficult. In addition, not all components are directly considered in all types of activity-based measures (see Table 1).

For evaluation purposes, researchers have discussed the accessibility measurements from two perspectives: objective and subjective. On the one hand, Geurs and van Wee (2004) propose an objective evaluation, based on changes in the service level of the transport modes, to assess demand and competition between opportunities and adaptability to the individual needs, abilities and opportunities. The authors' objective evaluation follows the trend proposed by Vickerman (1974), Wachs (1978), Badland et al. (2009), Curl et al. (2011) and Aditjandra et al. (2013), who are not in favour of the use of "outcome indicators" reflecting the behaviour of the population (e.g., current travel times) because they are based on the population's learning/adaptability to the current network conditions. 


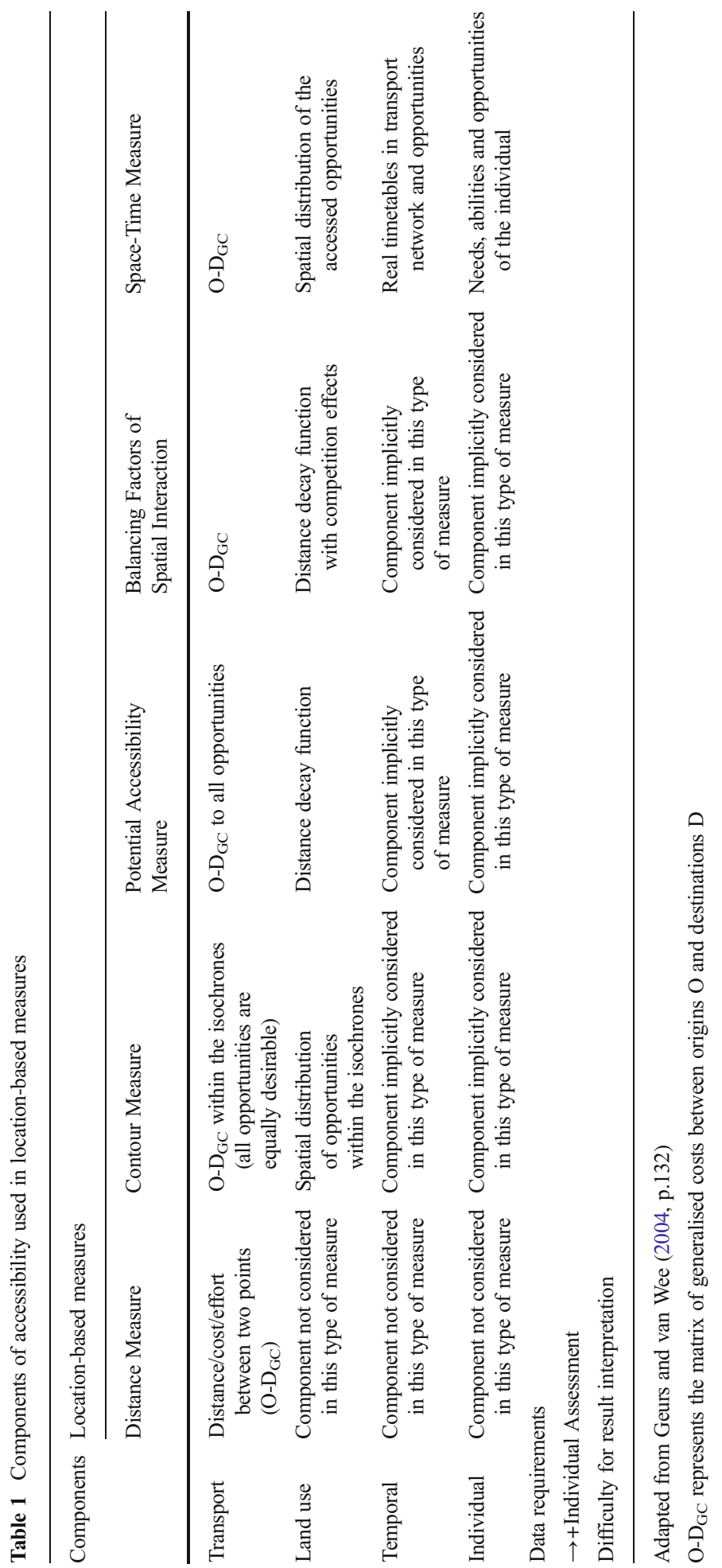


On the other hand, Handy and Niemeier (1997) and Bertolini et al. (2005) consider the subjective perception as a key element for the evaluation of accessibility. They argue for the need to incorporate "how residents perceive and evaluate their community" (Handy and Niemeier 1997, p. 1176) and "the uses and perceptions of the residents, workers and visitors of an area" (Bertolini et al. 2005, p. 210). Páez et al. (2012) show that both positive and normative approaches have their place and are useful to address specific needs: "by helping to understand in a positivistic way the current situation (e.g., identification of issues of possible policy interest), or to design, given a desired (i.e., normative) outcome, policy and planning interventions" (p. 142).

The focus of the current paper is on location-based measures. They are the most frequently used, because they can be calculated with data regularly collected by urban and transport planning departments/organisations. The review is highlighting a diversity of measures and approaches in measuring accessibility. Here we compare two contour methods previously used in accessibility assessment for public transport at the city level.

\section{Methods}

For the current analysis, two methods were selected for measuring accessibility: SAL and PTWAI. The selection was based on four criteria: (1) both methods are classified as location-based measures and presented using areas of similar access, which means their outputs are comparable; (2) the methods have been applied to evaluate the public transport accessibility in urban areas; (3) data required for analysis could be acquired from different sources available for Helsinki (in particular, HSL 2010; Jaakola et al. ${ }^{1}$ (2015); LIPAS 2013); and (4) the methods have been developed sequentially (PTWAI takes the SAL as a reference). A third method, LUPTAI, proposed by Yigitcanlar et al. (2007) was originally considered to be additionally integrated in the current study since it is a multi-contour measure and is aimed for measuring accessibility by public transport; however, due to data limitations it was not included in this paper.

Sections 3.1 and 3.2 are describing the methods as originally developed, and Section 3.3 how they were applied for Helsinki.

\section{The Structural Accessibility Layer (SAL)}

The SAL, proposed by Silva (2008), "assesses how urban structure constrains travel choices" (Silva and Pinho 2010, p. 2737). It includes the land-use and transport components, but not the temporal and individual components. It includes two accessibility measures, the diversity of activity index (DivAct) and a comparative accessibility measure (accessibility cluster) for categorization. It is expected the duplet to offer a better understanding of the land-use and transport conditions provided for mobility.

DivAct, based on the dissimilarity index proposed by Cervero and Kockelman (1997), measures the number of activity types reachable within a given threshold time.

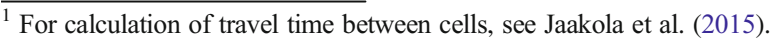


DivAct is calculated as the fraction of different services available in the area reached within a certain threshold time (relation 1$)$ :.

$$
\text { DivAct }=\frac{\sum_{i} A c t_{i} * f i}{\sum_{i} f_{i}}
$$

where $i$ is the type of activity (out of a set of 18), Act $t_{i}$ is a binary variable indicating whether the activity $i$ is accessible within the threshold time or otherwise, and $f_{i}$ their potential frequency of use.

Its range from zero (no accessible activities within the set boundaries) to one (all activities accessible within the threshold) shows how close residences are to a variety of activities considering a certain travel mode or combination of modes.

The results of the DivAct are consequently used to derive a comparative accessibility measure by travel mode. Three DivAct indices (for car C, public transport PT, and non-motorised NM modes) are plotted on a benchmarking cube, where each axis is divided into three categories, creating 27 classes, then amassed into nine accessibility clusters. These clusters define the availability of transport modes for reaching desired activities and their use simplifies the analysis by aggregating "conditions favouring the use of the same transport mode (or modes)" (Silva and Pinho 2010, p. 2738).

Given the purpose of this study, we use here only DivAct for public transport, therefore, it is expected that SAL's capacity to categorize accessibility in 27 classes and nine clusters is strongly under-used.

The comparative accessibility measure divides the DivAct index into three categories, A, B, and C: the benchmark (class A of high access) is the cumulative value of the potential use of opportunities/activity types not necessarily within walking distance (e.g., universities, non-food shopping, most leisure activities); class B ranges from the threshold values settled for class $\mathrm{A}$ in the upper limit to the value 0.50 in the lower limit; finally class $\mathrm{C}$ ranges from 0.50 to 0 . The accessibility classes are not mode specific, but rather reflect the "perception of the importance of activities in everyday travel and of the use frequency of these activities" (Silva and Pinho 2010, p. 2741). The thresholds are context specific, thus researchers may adopt other values better fitting their case study. Figure 1 provides the workflow for the SAL and PTWAI calculations undertaken in this study.

\section{The Public Transport Walking Access Index (PTWAI)}

The PTWAI is a measure used by Mavoa et al. (2012) to calculate accessibility for public transport and walking in New Zealand (the other indicator being a transit frequency index). The authors aimed to develop a tool for understanding public transit accessibility (access to destinations via public transit and walking modes), which is particularly important for encouraging mode shifts towards non-car travel. The PTWAI includes land-use, transport and partially temporal components (using actual timetables and an assumed waiting time). However, the individual component is not considered (for comparison of accessibility components between the two methods, see Table 2).

In contrast with SAL, PTWAI is destination based. Each land cell is scored on different services, based on how accessible they are. The range is 0 to 4 , where 4 


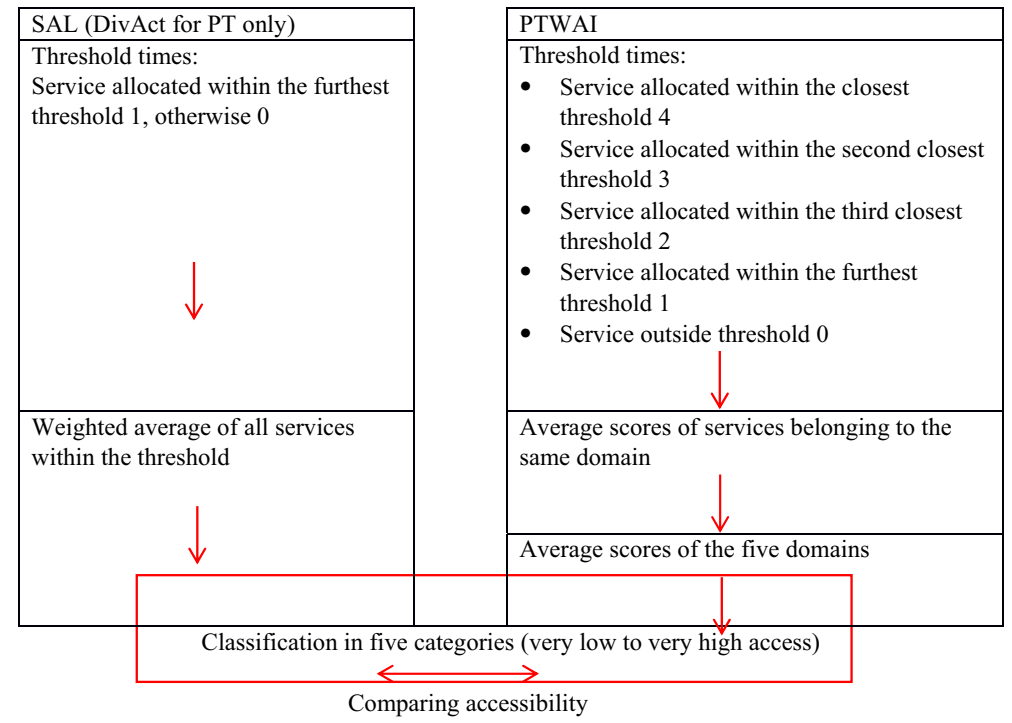

Fig. 1 Diagram of SAL and PTWAI calculations

represents the most proximal category $(<10 \mathrm{~min})$ where the services are located. For example, if the closest primary school is accessible by public transport within $15 \mathrm{~min}$ from an origin, the land cell receives a score of 3 . If the closest tertiary institution is reachable in $50 \mathrm{~min}$ by public transport, the score is 1 (Table 3). Then, PTWAI clusters services and its final score is calculated in two steps: 1) average of scores between services belonging to the same domain; and 2) sum of the scores between domains, as shown in Fig. 1. This means that for each land cell PTWAI receives a value between 0 and 20, where 0 indicates a completely inaccessible parcel and 20 means highly accessible (within an average travel time below $10 \mathrm{~min}$ ). The results of PTWAI are presented in five categories (very low to very high), each covering four points over the 0-20 range. In this sense, PTWAI could be indirectly considered a potentialaccessibility measure, since the scoring of the services, based on the category of isochrones, is similar to an indirect decay function.

\section{Adjustment for Making the Methods Comparable}

Original data for the study included a grid of 8,325 cells of $250 \times 250 \mathrm{~m}$ covering the metropolitan region of Helsinki. The size of the cells depended on the area having a

Table 2 Accessibility components included in the SAL and PTWAI methods

\begin{tabular}{lllll}
\hline Methods & Components & & & \\
\cline { 2 - 4 } & Transport & Land-Use & Temporal & Individual \\
\hline SAL & $\mathrm{X}$ & $\mathrm{X}$ & \\
PTWAI & $\mathrm{X}$ & $\mathrm{X}$ & $\mathrm{X}$ (indirectly) & \\
\end{tabular}


Table 3 Accessibility scores assigned for alternate travel time scenarios (Travel threshold times used in PTWAI and SAL)

\begin{tabular}{lll}
\hline Accessibility score & $\begin{array}{l}\text { Threshold times extracted from } \\
\text { Mavoa et al. (2012) (min) }\end{array}$ & $\begin{array}{l}\text { Threshold times extracted from } \\
\text { Salonen et al. (2014) (min) }\end{array}$ \\
\hline 0 & $>60$ & $>38$ \\
1 & $40-60$ & $25-38$ \\
2 & $20-40$ & $13-25$ \\
3 & $10-20$ & $6-13$ \\
4 & $0-10$ & $0-6$ \\
\hline
\end{tabular}

minimum of 10 residents per cell (Statistics Finland 2012), and the presence of opportunity points (LIPAS 2013; Service Map online). The cell size is comparable to Silva and Pinho's (2010) level of analysis, with an average census tract area of 6.25 ha, but smaller than the mesh-block applied by Mavoa et al. 2012 (an average of 51 ha).

To make the methods comparable, some adaptations were required. For example, the DivAct index for PT only was used in applying SAL, excluding car or non-motorised transport. This was needed to ensure consistency of SAL with PTWAI, which considers only access by the public transport system (for a more detailed explanation, see Salonen and Toivonen 2013). In this case study, both methods considered network-based access/ egress times to and from public transport, as well as timetable-based waiting and transfer times. This is similar to Mavoa et al.'s (2012) approach to PTWAI, but distinct from Silva (2008), who simplified waiting at the stops to a generic 5-min interval and the transfer to an equivalent to $100 \mathrm{~m}$ at maximum. Taking into account commuting times occurring on the network (and the actual schedule of transit services) increases the robustness of the methodology applied here and the results. As Lei and Church (2010, p. 289) suggest, "transit times can vary considerably over a network depending upon schedules, transfer times, etc.; so using network distance as a proxy for time may introduce considerable error". Thus, we expect these measurements to yield sounder indicators.

In addition, both methods used a common set of 28 opportunities (everyday destinations), combined into five domains: work/education, health, non-educational social services, shopping, and recreational purposes. The education domain contains six opportunities: universities and separated centres for preschool education, adult education, vocational education, basic education and secondary education. The health domain contains hospitals and health centres. The non-educational social services domain contains eight opportunities: centres for youth hobby, substance abuse, children's day care, social assistance, disabled care, elderly services, child and family welfare and employment care. ${ }^{2}$ The shopping domain contains only food shopping centres. Finally, the recreational domain contains 11 opportunities: theatres, restaurants, parks, religious buildings, museums, libraries, cultural facilities, morning and afternoon activities, sport centres and children's playgrounds (Service Map of Helsinki \& Espoo, 2014).

\footnotetext{
${ }^{2}$ The non-educational social services substituted the financial domain Mavoa et al. (2012) originally proposed, because data for those services were not available.
} 
Finally, two maximum threshold travel times were used in both models to compare the methods (Table 3). The threshold time for SAL (38 min) was obtained from previous travel surveys (Salonen et al. 2014) and represents the average trip time. Moreover, Salonen et al. (2013) showed that at least $10 \%$ of the population could reach local urban facilities, such as libraries, by public transport within 6 min (including walking, waiting and in-vehicle time). This may be explained by the short headways and high-density urban facilities in certain areas of Helsinki.

Because PTWAI is reported in five levels of access, the final SAL accessibility level was further refined and rescaled using five quantitative segments (index normalised to value one): "Very High" (index $\geq 0.85)$; "High" $(0.65 \leq$ index $<0.85)$, "Medium" $(0.45 \leq$ index<0.65), "Low" $(0.25 \leq$ index $<0.45)$ and "Very Low" (index< $<.25)$. As output of the measurement, four maps were created: a. SAL (60 min); b. PTWAI (60 min); c. SAL (38 min); and d. PTWAI (38 min), along with the differences between them.

PTWAI score is based on the averages of aggregate accessibility scores by domains. Thusly, opportunities contained in domains with fewer opportunities are weighted more in the final score than the opportunities within domains with more facilities..

Although adaptations were made, there is a fundamental difference between the two methods: whereas SAL offers a binary score (0 or 1$)$ for each transport mode (the activity type is accessible within the threshold or not), PTWAI offers a more refined score (from 0 to 4). Figure 2 displays graphically how DivAct and PTWAI accessibility scores are derived. This difference should be acknowledged when comparing the results from both methods, since SAL is a single contour measure, while PTWAI is a multi-contour measure. ${ }^{3}$

Section 4 describes the empirical setting for the comparison of the two methods.

\section{Case-Study Area}

Data from multiple secondary sources was used for analysis: geo-referenced land-use and transport data, census, and household travel survey indicators (Statistics Finland 2012; LIPAS 2013; HSL 2013).

The Helsinki Capital Region (HCR) is formed by the cities of Helsinki, Espoo, Vantaa and Kauniainen; in practical terms, the cities are meant to be a functional region with Helsinki as the main city. These four cities occupy $964 \mathrm{Km}^{2}$ and are home to one million residents (representing approximately $20 \%$ of the Finnish population).

The transport network for commuting within the HCR is diverse. The region follows a radial structure on train and tram infrastructure (Fig. 3), whose centre is at Helsinki Central Station. However, the bus network follows a more transversal distribution, due to the three ring roads (in yellow in Fig. 3) surrounding the HCR.

Public transport represents a key modal alternative in the Helsinki region, with a share of $43 \%$ of the total amount of trips. The number of trips by PT has increased to 355.5 million in 2013, and $80 \%$ of the population owns a Travel Card or other public transport pass (HSL 2013).

\footnotetext{
${ }^{3}$ One of the reviewers pointed out this aspect and generously offered an earlier version of Figure 2, which we adapted and extended for this publication.
} 

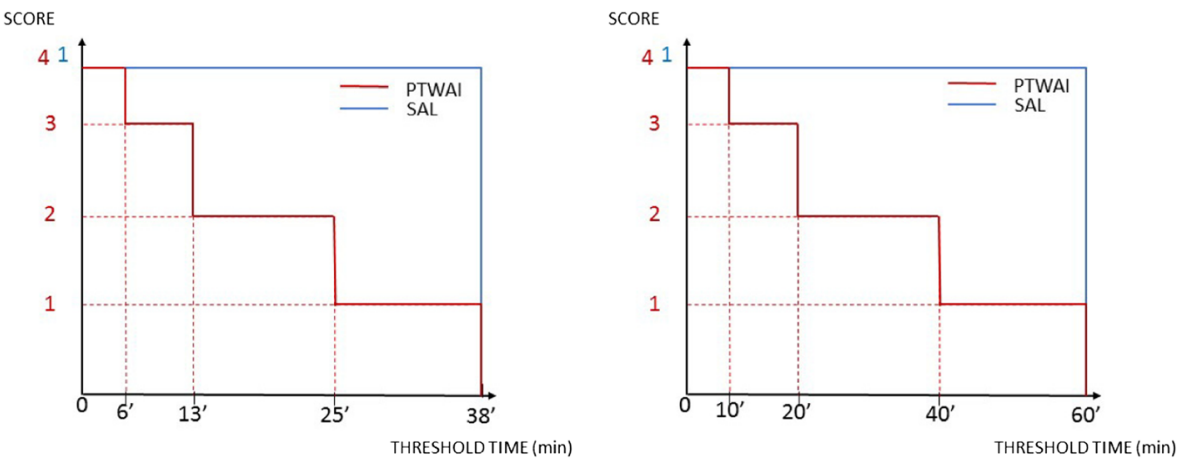

Fig. 2 Score distribution for SAL (single contour, in blue) and PTWAI (multiple contour) for threshold values of 38 and $60 \mathrm{~min}$

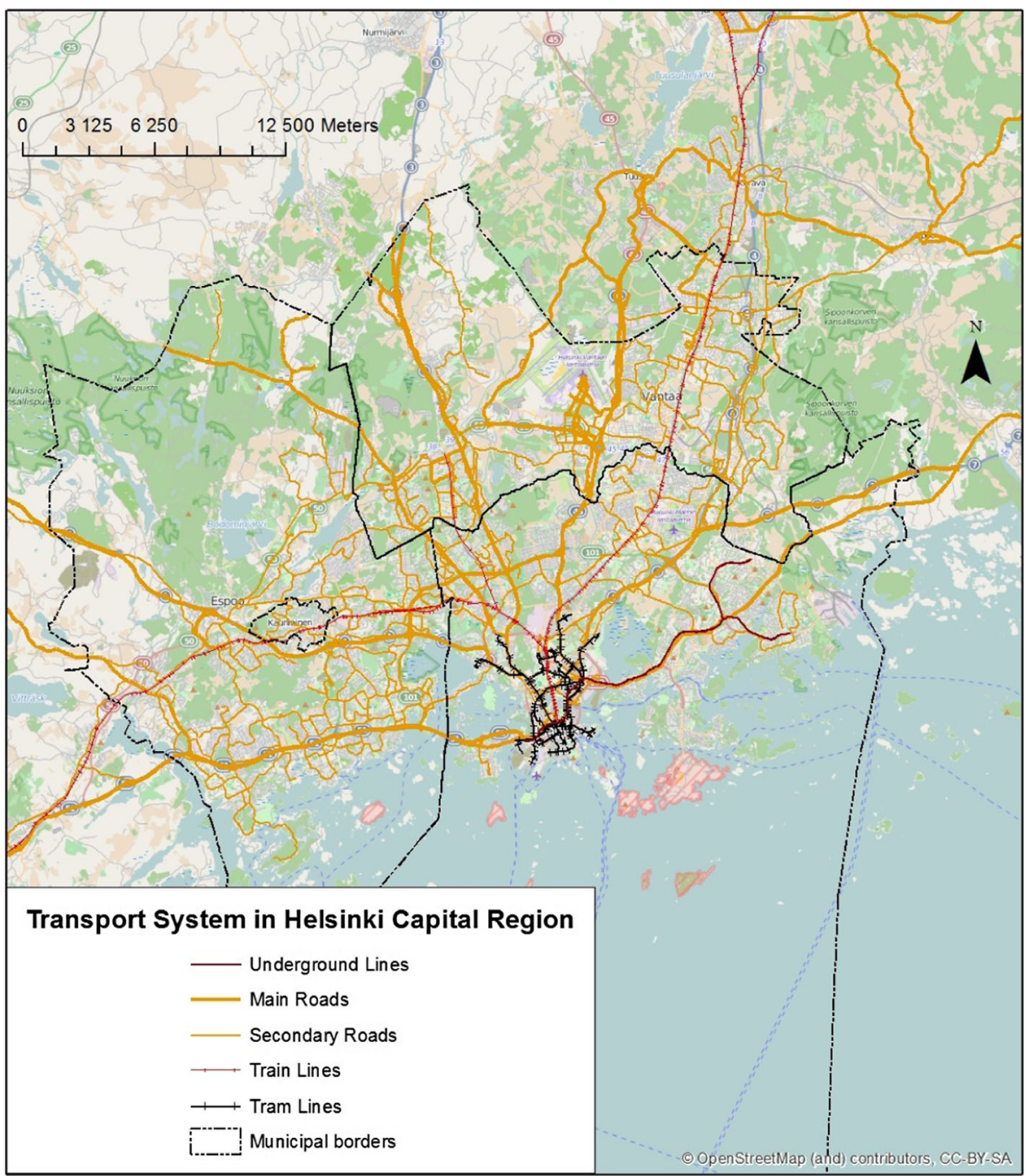

Fig. 3 HCR cities and transport network 
The 2013 distribution of public transport passengers indicates the dominance of bus ridership (50.6\%), followed by heavy and light rail (17.8\% by metro; $15.9 \%$ by tram; $15.1 \%$ by commuter train) and $0.5 \%$ by ferry.

To varying degrees, Helsinki's residents use walking, cycling, car, PT and other transport modes, depending on the purpose of travel and the modes available between origins and destinations (see HSL 2010). During working days, six activities (home, work, school, shopping, leisure and work related) prevail. Table 4 shows that two-thirds of the trips are made from home for commuting, shopping and leisure activities.

\section{Results}

The analysis includes three parts:

- mapping of SAL and PTWAI accessibility measures and direct comparison (for two different accessibility thresholds, 60 and $38 \mathrm{~min}$ );

- analysis of the relationship between accessibility and socio-economic characteristics;

- $\quad$ summary/descriptive statistics of accessibility measures.

\section{Comparing SAL and PTWAI}

We obtained accessibility classes by aggregating the average scores of the domains in the case of PTWAI (Table 3) and by normalizing the diversity of activities (DivAct) level proportionally to the thresholds of the categories described in PTWAI. Although similar input values were used and the application of the two methods had similar objectives, different results were obtained, mainly due to the difference between singlecontour and multi-contour characteristics of SAL and PTWAI.

The resulting accessibility classes were differently distributed between methods: the SAL output resulted in more cells classified as very high accessibility levels than the PTWAI analysis (see Figs 4 and 5). Most Helsinki areas have very high accessibility to

Table 4 Proportion of trips during working days within the HCR

\begin{tabular}{llllllll}
\hline O/D & Home & Work & School & Shop & Leisure & Work related & Total origins $\%$ \\
\hline Home & 6 & 23 & 10 & 20 & 23 & 1 & 83 \\
Work & - & 1 & 0 & 2 & 3 & 1 & 8 \\
School & - & - & 0 & 1 & 1 & 0 & 2 \\
Shopping & - & - & - & 2 & 3 & 0 & 5 \\
Leisure & - & - & - & - & 3 & 0 & 3 \\
Work related & - & - & - & - & - & 0 & 0 \\
Total Destinations $\%$ & 6 & 24 & 10 & 25 & 33 & 2 & 100 \\
\hline
\end{tabular}

Adapted from HSL (2010, Fig. 27) 
the five classes of destinations by public transport using SAL measures. Yet, only a small part of Helsinki (the city centre) appears to have high access according to the PTWAI metrics.

Moreover, the spatial distribution of the classes differed between the resulting maps. In SAL (Fig. 4), the "very high" accessibility class seems to be mainly located within the ring roads, whereas when using PTWAI (Fig. 5), the same accessibility class appears only in the CBD of Helsinki and in small areas surrounding the underground stations located in Vantaa (east of Helsinki). The map is consistent with the population density (see Fig. 6).

Figure 7 presents the map of differences between the SAL and PTWAI accessibility values for easier interpretation.

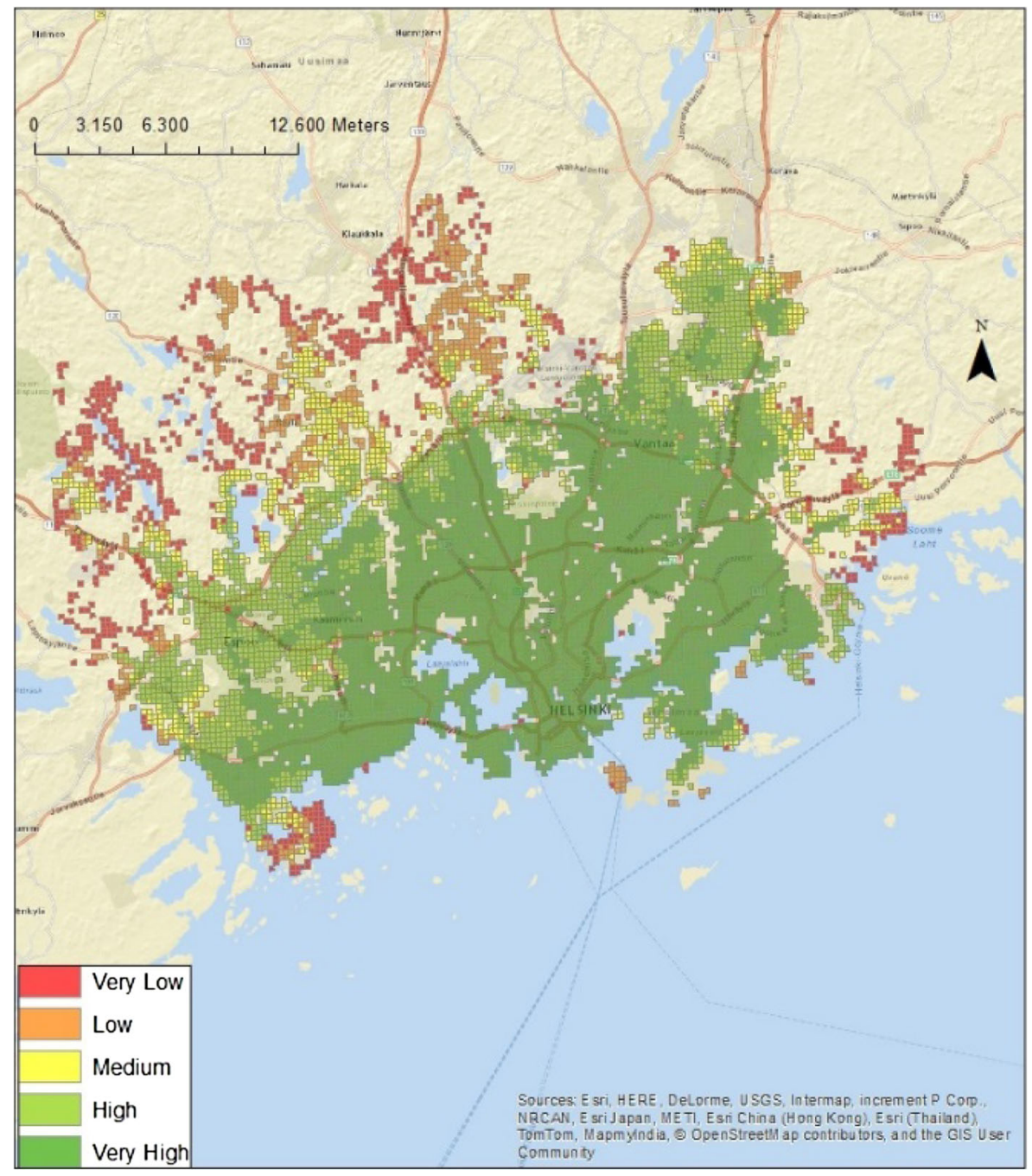

Fig. 4 Accessibility classes in HCR SAL using PTWAI threshold time (SAL 60) 


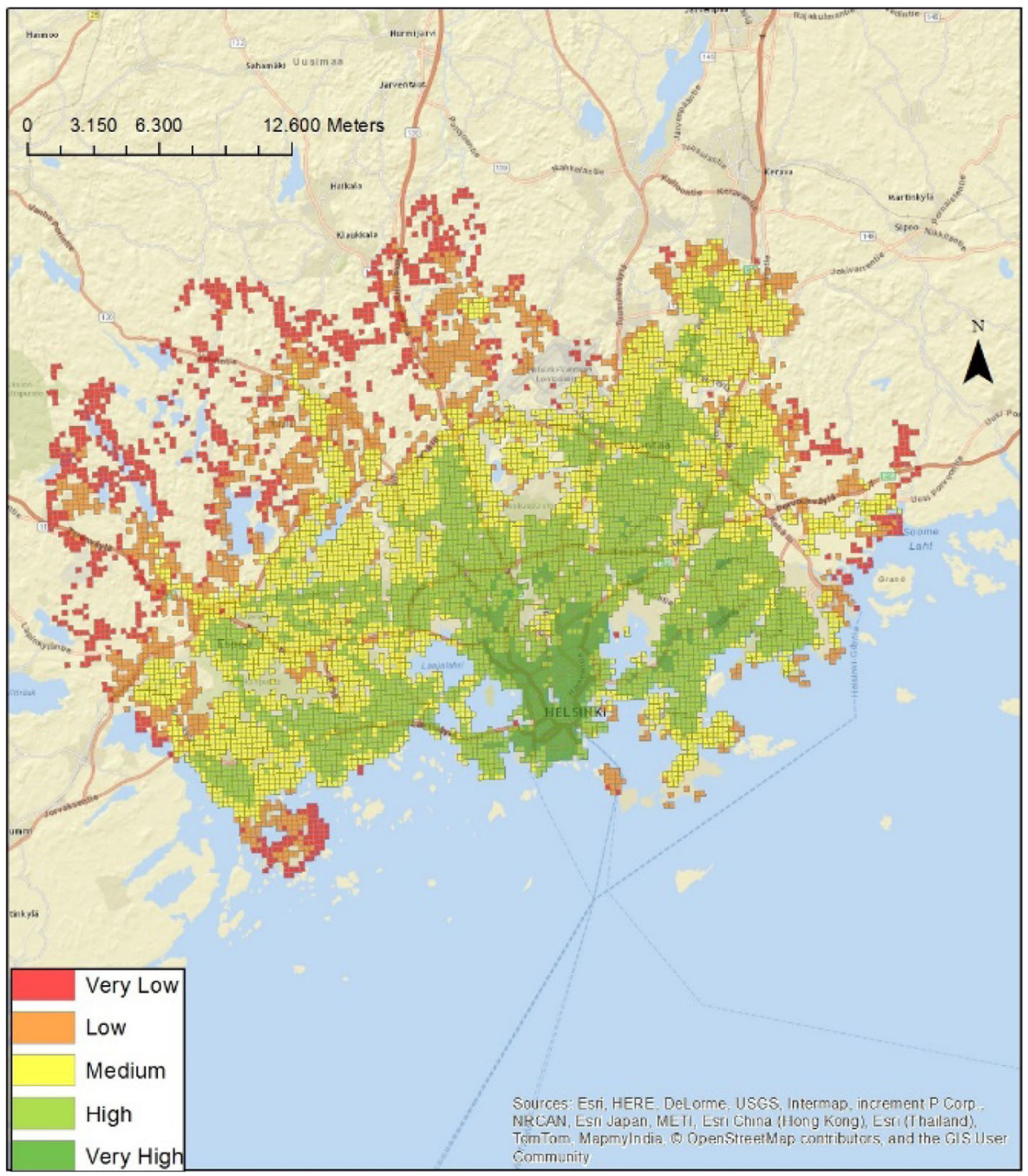

Fig. 5 Accessibility classes in HCR using PTWAI (PTWAI 60)

The most populated areas have the highest PTWAI access, reflecting equitable, wellthought-out planning decisions. There is also good access for the highest income zones in the west but not in the east.

With very few exceptions (northwest suburbs, at the end of the train lines and the southwest harbour), PTWAI accessibility is lower than SAL. The largest differences are for the southwest area close to Espoo, an area of low density and socio-economic status.

When repeating the analysis using the proposed threshold time for SAL (38 $\mathrm{min}$ ), the accessibility categories for both methods dropped (Figs. 8 and 9), as expected.

The same spatial pattern of the accessibility categories remains as previously observed for $60 \mathrm{~min}$ in Figs. 4 and 5, with a more pronounced border effect around the ring road (Fig. 8) and train and underground stops (Fig. 9). A difference map (Fig. 10) is provided for clearer visualisation of the areas under or overestimated accessibility by the two methods. 


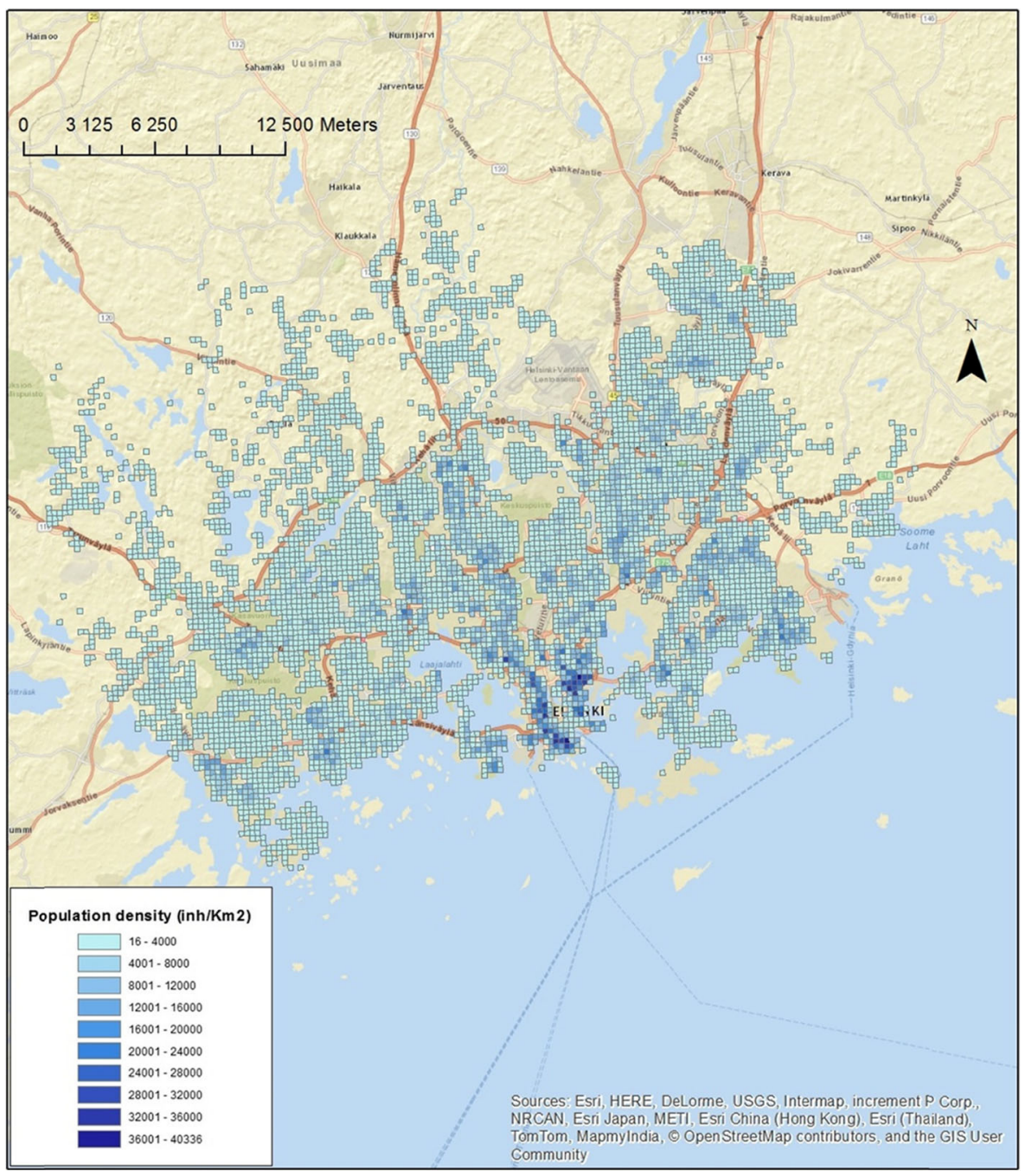

Fig. 6 Population density in HCR

Notably, whereas Fig. 7 shows that both methods produce the same results for the central area of Helsinki, Fig. 10 suggests relative convergence of the two methods for the suburban areas.

\section{SAL, PTWAI, and Socio-Demographic Characteristics}

A specific objective of this study has been to find how the metrics/methods perform in identifying population groups that are less well catered by public transport.

Table 5 profiles the five levels of accessibility zones based on socio-demographic characteristics. The SAL indicator offers a more optimistic view of the accessibility than the PTWAI indicator for both 60- and 38-min accessibility levels. 


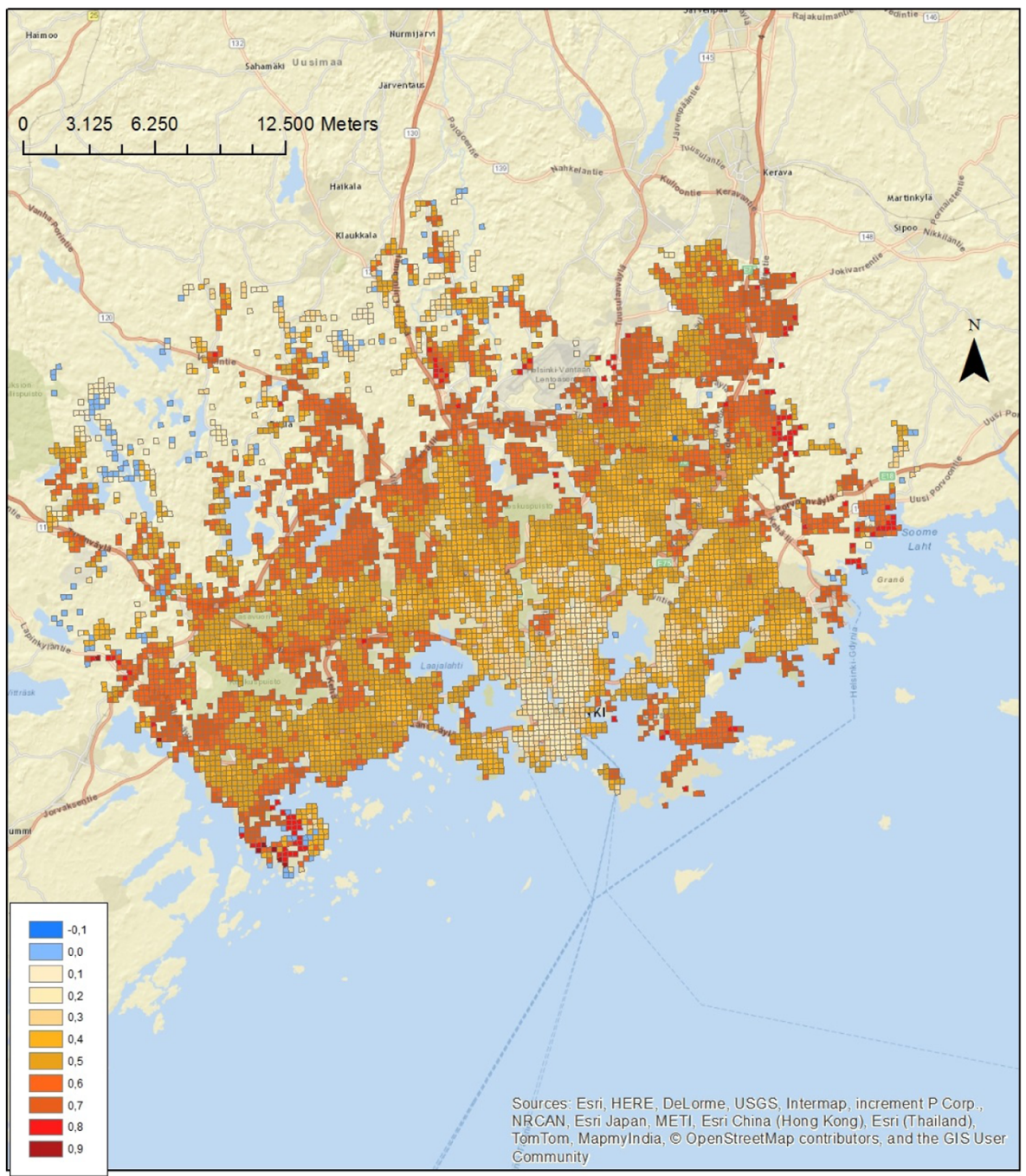

Fig. 7 Difference Accessibility SAL-PTWAI (60)

In terms of general accessibility, the results in Helsinki are comparable with Mavoa et al.'s (2012) findings for the Auckland region: more than $80 \%$ of the population and more than $90 \%$ of the families with children live in areas with medium-high public transport. However, the urban population living in areas with lower accessibility is younger (29-32 years), which suggests that some measures for inclusion are needed (see Fig. 11).

PTWAI measures are more refined and the results appear more conservative, with the 38-min isochrones indicating low and very low access for $35 \%$ of the population, primarily households with children (43\%). The SAL measures indicate very high accessibility for $>77 \%$ of the population and $72 \%$ of the households with children, whereas PTWAI display that most of the population 


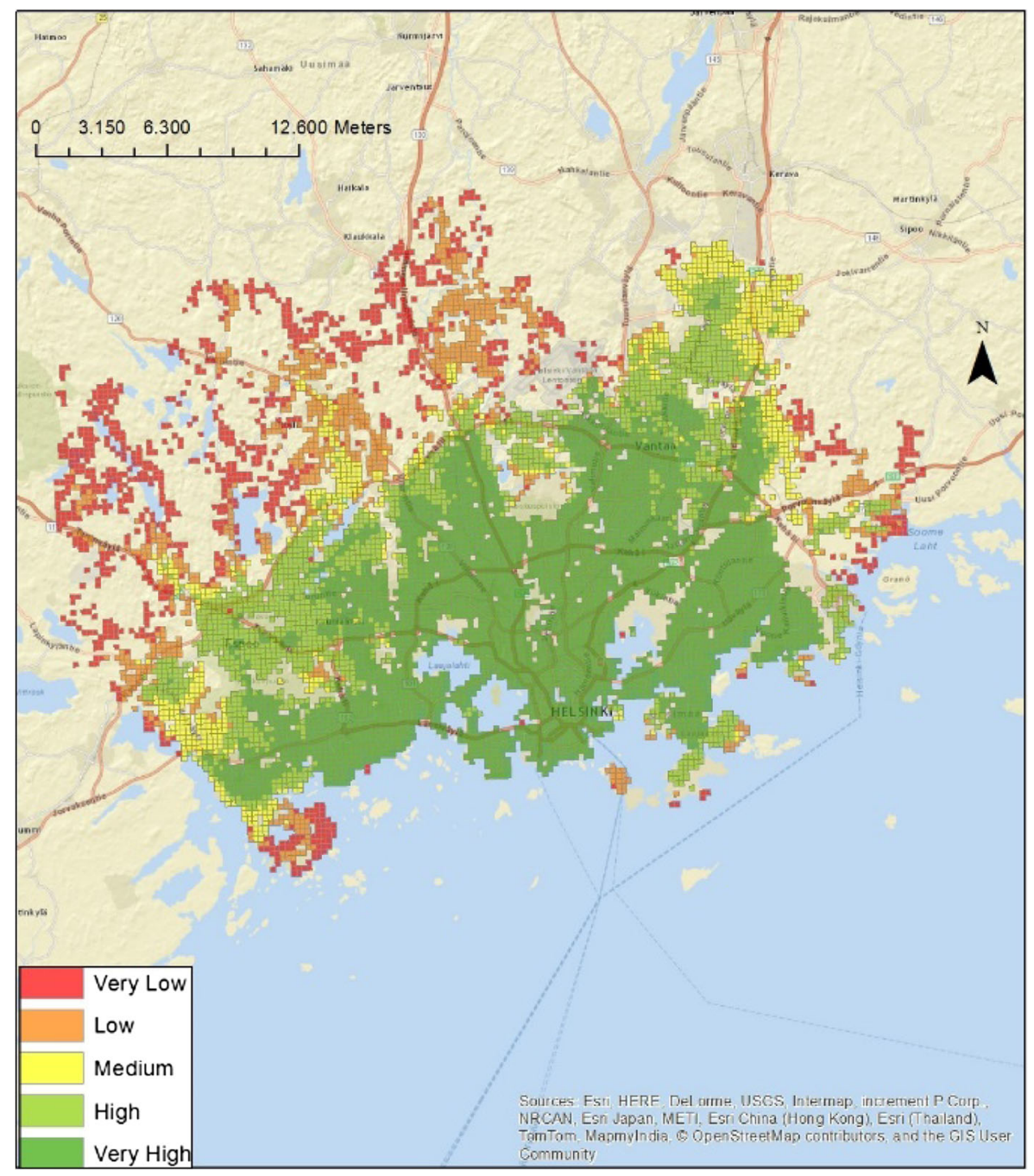

Fig. 8 Accessibility classes in HCR using SAL (SAL 38)

resides in medium to high access. The profiling of the areas also shows that people living in areas of very high PTWAI access are older than in areas identified as highly and very highly accessible by SAL. In addition, the distribution of pensioners is distinct between the two sets of maps: whereas most pensioners live in very high access areas, as identified by SAL, only a small fraction of them are included in the residential areas of very high access with PTWAI. This spatial distribution also contributes to the contrasting results for the median income of the residents. Surprisingly, the highest median income seems to appear for the residents living in medium and high SAL access areas, but lowmedium PTWAI areas. The finding, along with the positive association between average household age and income, may be indicative of the life-cycle stage of the 


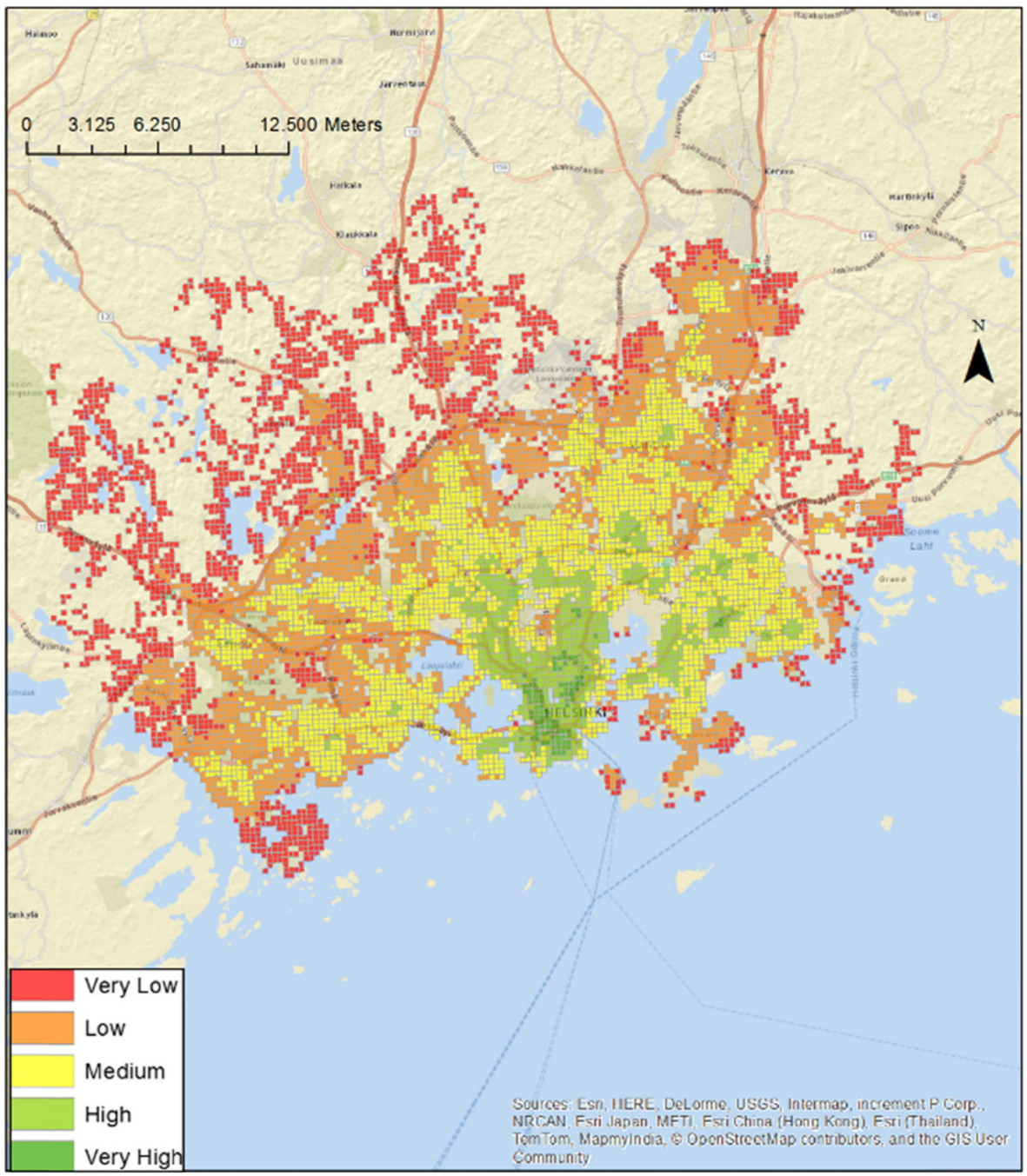

Fig. 9 Accessibility classes in HCR PTWAI using SAL threshold time (PTWAI 38)

population group living in a certain area; with couples with children and senior couples seeking higher access than young individuals and couples.

The dissimilar results between SAL and PTWAI 38 have considerable implications for the usage of these methods for analysing the level of accessibility by public transport. As it can be observed from Figs. 6 to 9, the resulting indexes from SAL are overestimating the accessibility compared with the result index obtained from PTWAI. In addition, the areas where both methods bring similar results correspond only to the zones where there is a high density of services.

As Fig. 2 suggests, the single contour nature of SAL cannot be expected to produce the same level of variation in the output as PTWAI. In order to minimise the effects on the methodology, it is of special interest to compare the results from PTWAI using $60 \mathrm{~min}$ as threshold time with SAL using $38 \mathrm{~min}$ as 


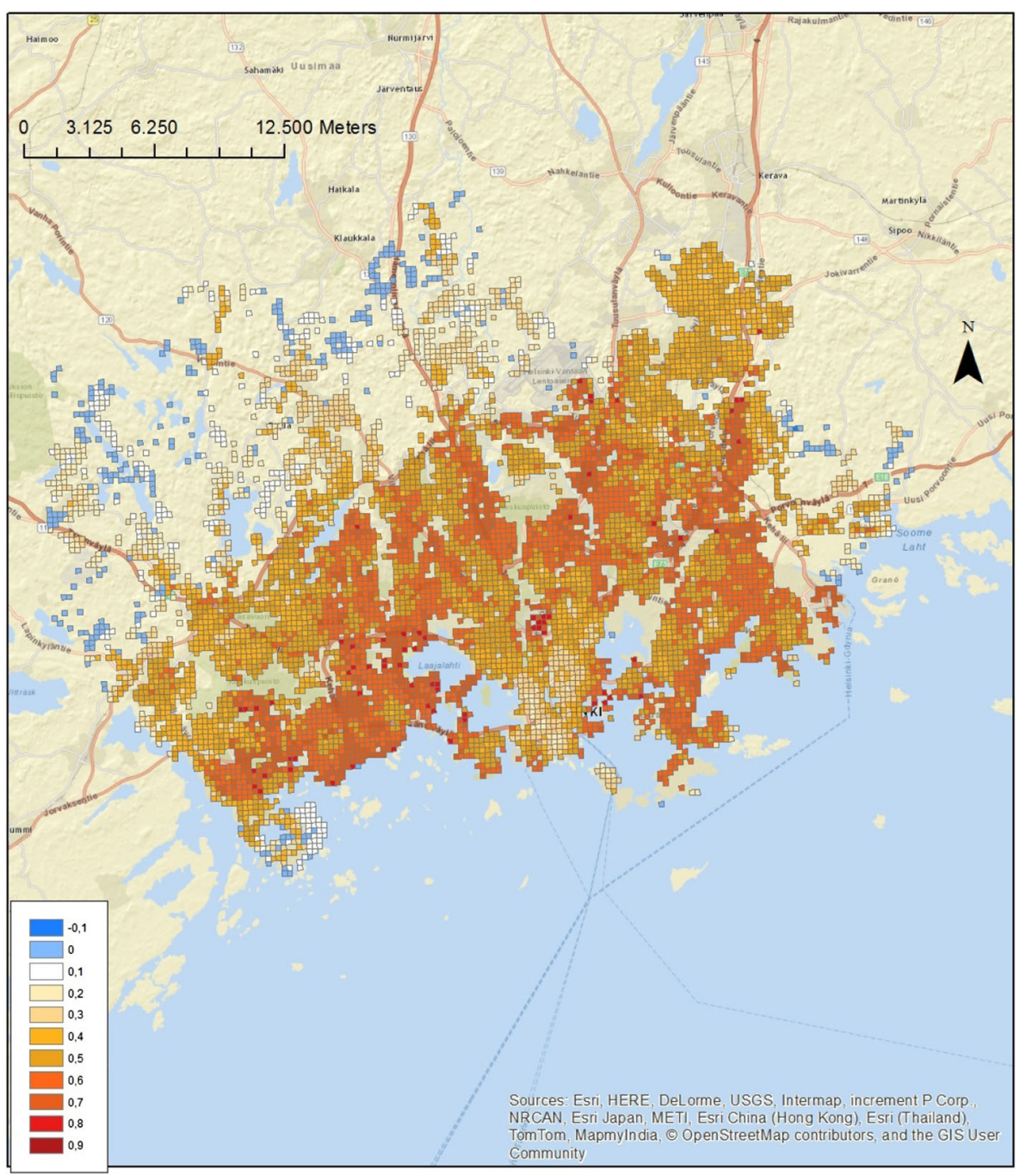

Fig. 10 Difference Accessibility PTWAI - SAL (38)

threshold time. In this way, the binary effect of SAL is reduced when selecting the minimum threshold time and the diversity in the results from PTWAI is minimised by using the maximum threshold time $(60 \mathrm{~min})$. When looking at the results presented in Table 5, the difference in the percentage of population and of households with children remains substantial. SAL presents $77.92 \%$ of the population residing in very high accessibility index whereas in PTWAI is only $12.41 \%$ of the population. A similar result is observed for the percentage of households with children, while SAL presents $72.08 \%$ of the households as living in areas with very high accessibility index, in PTWAI it is on $6.91 \%$ of them living in areas of the same category. Overall, PTWAI (60 min) suggests that the prevailing accessibility level is medium. 


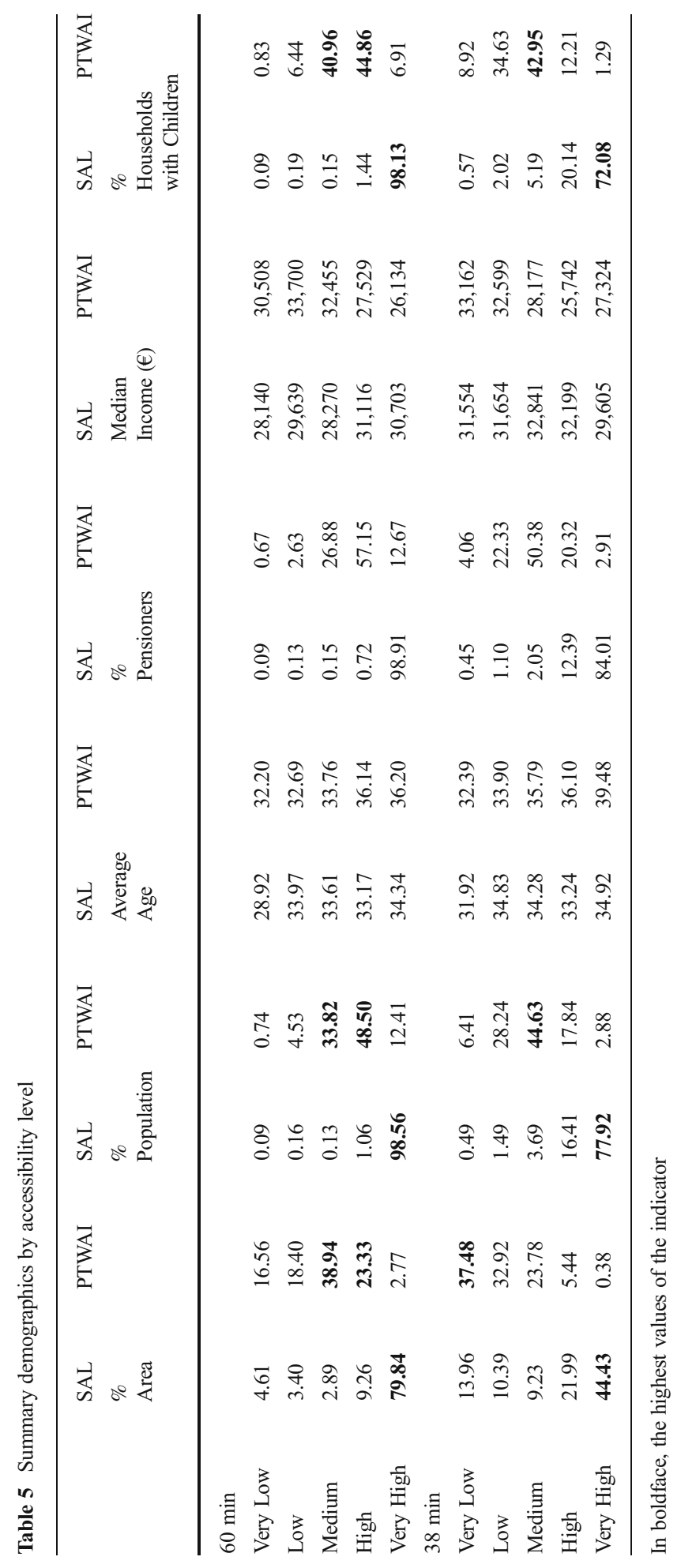




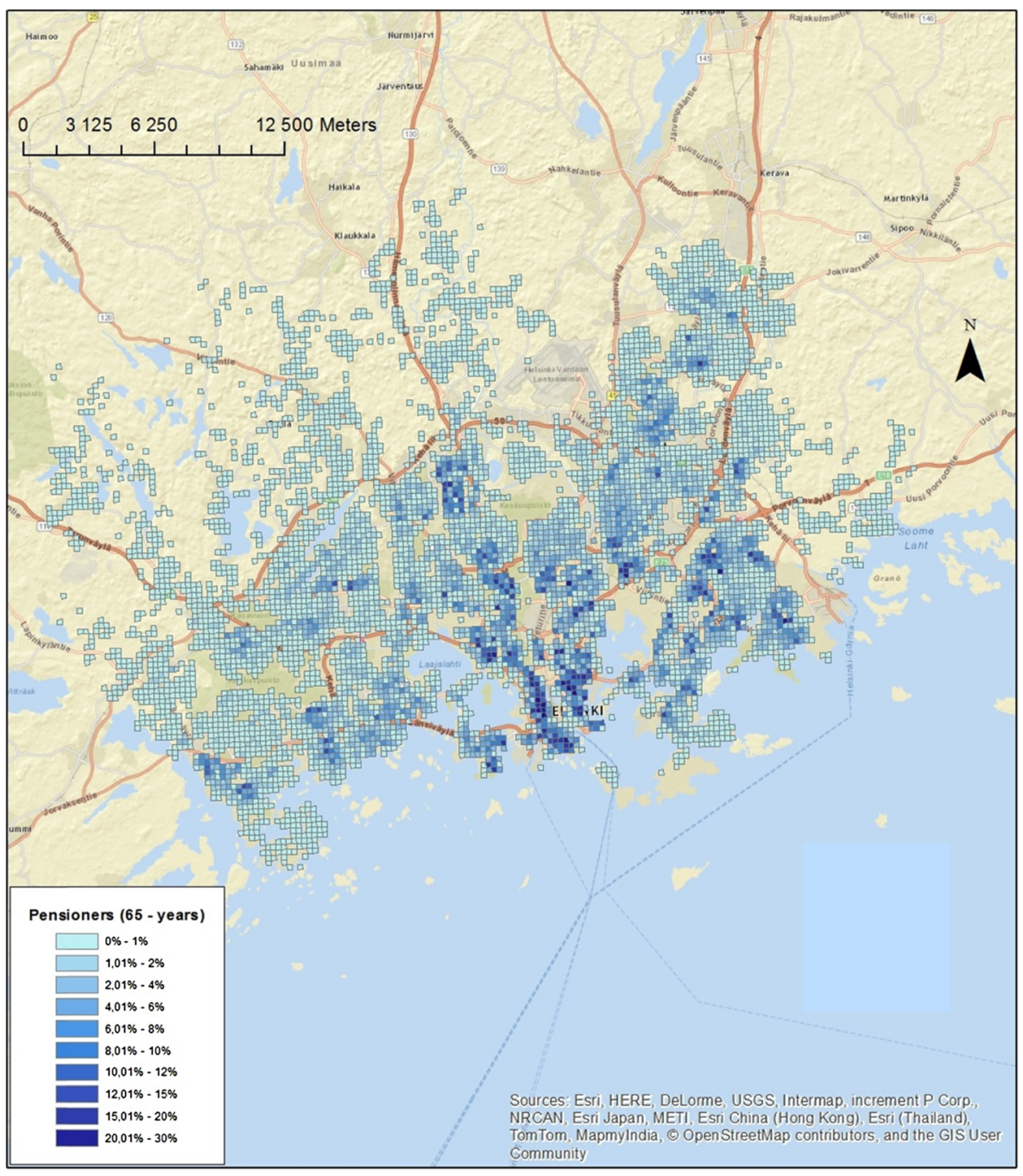

Fig. 11 Proportion of senior residents (aged 65+) in HCR

\section{SAL and PTWAI Distributions}

To further compare the accessibility outcomes, we used the same categories for the resulting accessibility index and plotted their frequencies (Fig. 12). As expected, both methods show sensible changes in the outcome accessibility index when modifying the threshold times. However, because of its derivation, SAL measure displays a high negative skewness, with highest frequency of cells being in the highest accessibility class. Alternatively, for the PTWAI, the distribution of frequencies follows a more normal distribution, with a larger amount of cells with low accessibility index. When reducing the threshold from 60 to $38 \mathrm{~min}$, both PTWAI and SAL distributions are less skewed and kurtotic, although SAL remains negatively skewed. 

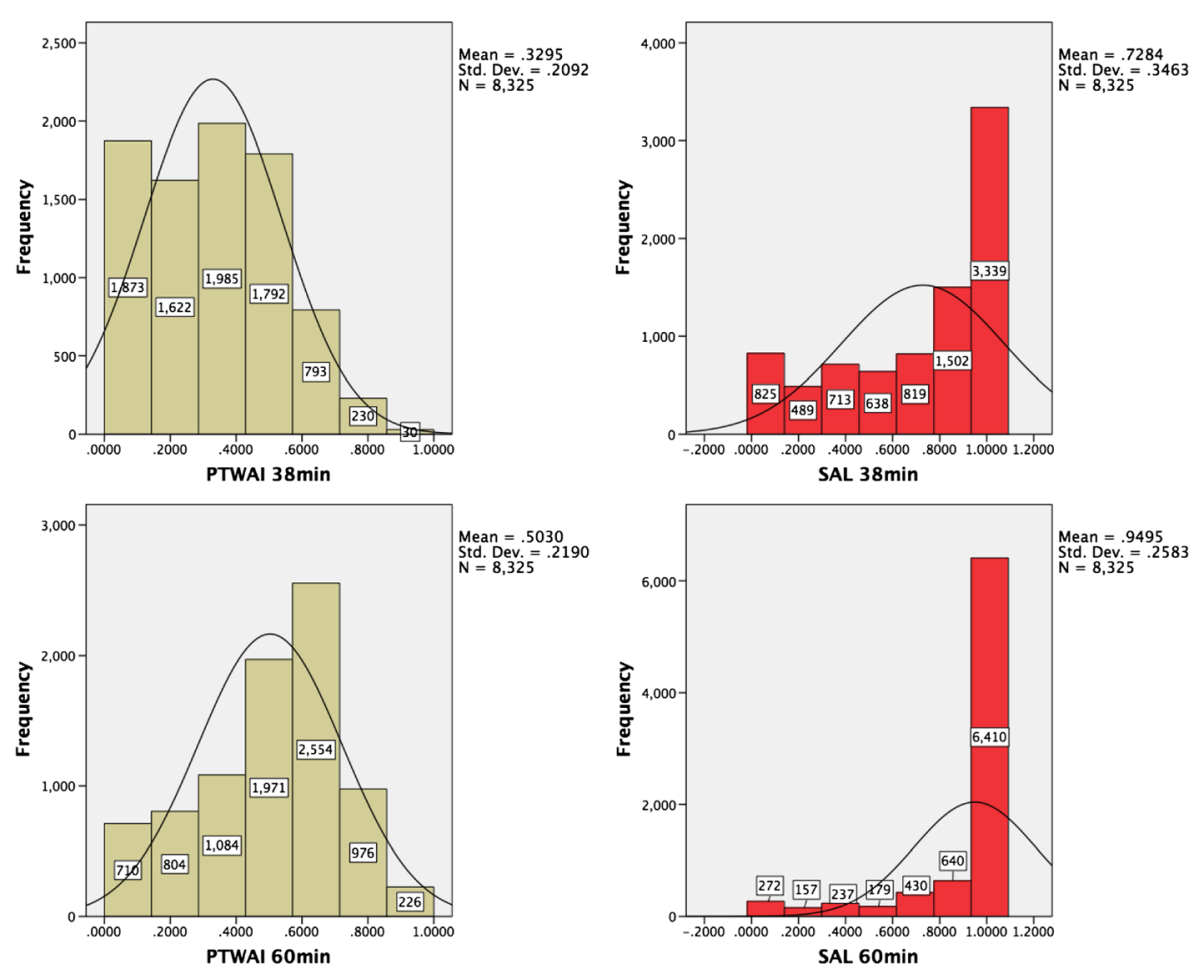

Fig. 12 Histogram of frequency of cells in the normalised accessibility index

The distributions presented in Fig. 12 support the discussion on how both methods are calculated and applied. The multi-contour nature of PTWAI allows a finer level of disaggregation of the measures prior to calculating the final index and the output appears to follow a normal distribution of the final accessibility indexes. Conversely, the single-contour nature of DivAct in SAL increases the dependency of the method on the type of services included for the final index calculation and its distribution of the final accessibility index tends to be shifted towards extreme values.

\section{Discussion}

The aim of this study is to adapt, test and evaluate the policy implications of alternate location-based accessibility measures for public transport for the case study of Helsinki metro area. The current article compared two operational methods, SAL (Silva 2008) and PTWAI (Mavoa et al. 2012), to assess their advantages and limitations and clarify their usability.

The methods were adapted to ensure direct comparability and improved by considering traffic conditions instead of timetabled times. The analysis started with visualising and quantifying the accessibility provided by the PT system and land-use in the Helsinki metropolitan area (separate for SAL and PTWAI), then it compared the results of the two methods. 
The common spatial resolution, the set of opportunities and travel times of the two methods allowed us to discard potential effects of those variables on the final results. Our results suggest that accessibility calculated following PTWAI method show a more normal distribution due to the multi-contour measure of the method, with maps clearly showing areas with potential easy access to the public transport network; the results of SAL method are more aggregated due to a single-contour measure of the method, and as such the resulting maps are more homogeneous. When both methods used the same threshold values (60 and $38 \mathrm{~min}$ ), set of opportunities and combination of access to different opportunities, the access measures, scoring components separately, offered more detailed accessibility maps. As Geurs and van Wee (2004), p. 137 suggest, "the interpretation can be much improved by estimating the separate influence of the different components of accessibility". This relevant difference explains the final performance of the methods. PTWAI offers moderate estimations, whereas SAL presents a more positive perspective of the city accessibility.

These results clearly reflect the original intention and derivation of the SAL and PTWAI indicators, but the novice may ponder that either method should lead to the same conclusions. The distinct insights challenge the user, question the robustness of the findings and call for cross-validation. The differences in spatial distribution and socio-demographics between the two methods suggest that these methodologies are sensitive to inputs, space and time and they should be further explored. Given the relevance and utility of accessibility measures to guide policy making in urban areas, to promote more sustainable transport solutions, identify areas potentially disadvantaged/ excluded ${ }^{4}$ and observe the effects of future transport systems and land-use changes in accessibility, it is key to develop, test and validate methodologies that can be easily implemented in planning practices. Replication and cross-validation are indispensable parts of a modelling toolkit that can lend support to the credibility of the approaches.

In terms of practical use, the findings can inform planning. Mode substitution towards PT is likely to be more feasible in locations with high PTWAI. Attempts to encourage mode substitution in locations with low PTWAI (in orange and red in Fig. 5, the southeast and north areas of the HCR) are unlikely to be successful. Thus, the PTWAI and SAL maps provide insights into locations where public transport improvements could be prioritised to increase the overall accessibility of Helsinki's population.

\section{Limitations and Further Directions}

This research adapted, applied, and compared two accessibility measures of public transport accessibility in Helsinki. The findings of this research imply that PTWAI is more suitable to planning assessments than the DivAct of SAL, given its relatively richer content. However, it is worth mentioning that the original goal of SAL is not to measure the accessibility by public transport, but to categorize accessibility by using three types of transport modes. If more travel modes were included in the study, SAL would work better than PTWAI. Additionally, in terms of computation, SAL requires lighter proceeding work since the DivAct index for each transport mode depends only

\footnotetext{
${ }^{4}$ Although the focus of the current research is sustainability, we acknowledge that a significant importance of PT accessibility relates to equity issues.
} 
on a single threshold; while in the case of PTWAI the calculation is not so straightforward.

A major limitation of the analysis is that the transport component is applied considering only the opportunities within the isochrones (threshold times) and giving all of them the same relevance. Although Vickerman (1974) and Ben-Akiva and Lerman (1979) pointed out this shortcoming decades ago, the relatively simple derivation of accessibility remains a major appeal for many jurisdictions. The PTWAI method provides evidence that scoring the different time values allows a degree of qualitative discrimination between destination cells. Nevertheless, the PTWAI method does not completely overcome other important limitations in contour measures regarding the allocation of the threshold levels for the isochrones categories, as well as the need to assess the actual attraction of the opportunities in the area. This method may lead to an overestimation of accessibility. Ideally, accessibility could be calculated at the individual/household level.

The same principle applies to the land-use component. Whereas in SAL the existence of a single opportunity within the threshold time increases the final DivAct index, in PTWAI such diversity is indirectly scaled according to the score values given to the different isochrones. Nevertheless, it is also true that PTWAI does not account for the variation in access level provided by the same type of opportunities, because only the highest valued isochrones that encompass the destination cell are considered in the final accessibility score. Therefore, because both methods rely to a great extent on land-use mix, in the cases where certain opportunities were spatially clustered and benefitted from good public transport and walking connections, the final result from both methods is expected to be similar.

Additionally, the additive nature of PTWAI conceals circumstances. When an area presents high access to for example shopping, social, and recreational facilities; and average access to education, health and financial services; the area scores equally to another area where the situation is vice versa. Obviously, the combinations of services meet distinct needs. The former location may be appealing for young couples, whereas the latter may be highly sought by households with children. However, our PTWAI and SAL results represent indices for a generic average individual/household with the same needs, preferences and constraints.

This highlights the need for accessibility measures to account for the individual/ personal component, as recommended by Kwan and Weber (2003) and Curl et al. (2011). Individual perception of accessibility (Curl et al. 2011; Stanley and VellaBrodrick 2009), heterogeneity in individual circumstances (Kwan and Weber 2003), and soft barriers (Hine and Mitchell 2001; Lucas 2006) have been shown to have a relevant role in accessibility.

Regarding the temporal component, we calculated the commuting time between origins and opportunities for regular weekdays, at nonpeak hours, without including congestion effects. This assumption that public transport services are available at the same frequency as in the peak period and unaffected by car travel, is another limitation of the study. However, data availability prevented further exploration of this aspect.

To effectively map the accessibility in a given transport and land-use system, policy makers and urban planners should not limit themselves to single time values; rather, they should test for potential access to destinations by public transport and walking using a range of times/costs required to reach those opportunities, in this sense, the 
multi-contour nature of PTWAI allowed certain disaggregation of the results. For urban planners, the possibility of automation in building PTWAI maps would allow what-if scenarios by modifying the land-use component within the existing transport system. However, none of the methods should be used as an expression of actual accessibility for citizens, because they do not consider relevant temporal and individual components.

Although this research indicates that PTWAI appears more detailed and sensitive to landuse and transport changes when measuring accessibility with a single transport mode, further progress is required to account for individual and temporal constraints for effective evaluation of opportunities, to obtain a more fine-grained analysis of a population's mobility needs.

To include the individual component (moving down in Table 1), urban planners and policy makers could use individual surveys to evaluate whether the availability of the travel mode alone is enough to persuade travellers to choose PT considering their personal circumstances. Likewise, the methods compared in this paper did not take into account trip-based measures, neglecting multi-purpose trips and trip chaining. Future research comparing them may highlight substantial differences in the accessibility results.

Another limitation of our research is the spatial resolution we used. As Handy and Niemeier (1997) suggest, we disaggregated the data as much as possible; however, perhaps an optimal resolution level would go further, considering the actual origins and destinations of travellers. In any case, analysts must assess the optimal level of disaggregation on a case-by-case basis, using the specific geographical setting and data availability. Given that accessibility level within a cell does not vary, we argue that the smaller the area the better; however, the topography and population/employment density may indicate otherwise. If possible, a sensitivity analysis of the role of applying various spatial data resolution levels (e.g., aggregating cells in larger geographical units, using administrative boundaries) needs to be investigated.

Finally, more research is needed to compare contour-based accessibility methods to assess those elements to be considered for further improvement of the methods. To this end, potential research could be conducted on the comparison of the present methods with the Land Use and Public Transport Accessibility Indexing Model (Yigitcanlar et al. 2007). In terms of application, it is the analyst's role to choose the tool fit-forpurpose. A judgement should be made on the trade-off between the detail of the measures and results and the computational burden, for a given objective.

Acknowledgments This work was supported by the Rakennetun Ympäristön Tohtoriohjelma (RYM-TO) [T20500/913615/RYM-TO]; Kunnallisalan Kehittämissäätiö (kaks.fi) and the Helsinki Metropolitan Region Urban Research Program (KatuMetro). The authors thank the reviewers and the editor for their detailed feedback and valuable insights, which have helped them to improve the manuscript and also to Mr. Andrew Lo for the invaluable support.

Open Access This article is distributed under the terms of the Creative Commons Attribution 4.0 International License (http://creativecommons.org/licenses/by/4.0/), which permits unrestricted use, distribution, and reproduction in any medium, provided you give appropriate credit to the original author(s) and the source, provide a link to the Creative Commons license, and indicate if changes were made.

\section{References}

Aditjandra, P. T., Mulley, C., \& Nelson, J. D. (2013). The influence of neighbourhood design on travel behaviour: empirical evidence from north east England. Transport Policy, 26, 54-65. 
Axhausen, K. W. (2007). Activity spaces, biographies, social networks and their welfare gains and externalities: some hypotheses and empirical results. Mobilities, 2(1), 15-36.

Badland, H. M., Schofield, G. M., Witten, K., Schluter, P. J., Mavoa, S., Kearns, R. A., Hinckson, E. A., Oliver, M., Kaiwai, H., Jensen, V. G., Ergler, C., McGrath, L., \& McPhee, J. (2009). Understanding the relationship between activity and neighbourhoods (URBAN) study: research design and methodology. BMC Public Health, 9, 224.

Ben-Akiva, M., \& Lerman, S. R. (1979). Disaggregate travel and mobility choice models and measures of accessibility. In D. A. Hensher \& P. R. Sopher (Eds.), Behavioural travel modelling (pp. 654-679). Andover: Croom Helm.

Ben-Akiva, M., \& Lerman, S. R. (1985). Discrete choice analyses: theory and application to travel demand. Cambridge: MIT Press.

Bertolini, L., Clercq, F., \& Kapoen, L. (2005). Sustainable accessibility: a conceptual framework to integrate transport and land use plan-making Two test-applications in the Netherlands and a reflection on the way forward. Transport Policy, 12, 207-220.

Bhat, C., Handy, S., Kockelman, K., Mahmassani, H., Gopal, A., Srour, I., \& Weston, L. 2002, "Development of an Urban Accessibility Index: Formulations, Aggregation, and Application", Report 4938-4 University of Texas at Austin, http:/www-dtp.cc.utexas.edu/research/ctr/pdf_reports/4938_4.pdf.

Breheny, M. J. (1978). The measurement of spatial opportunity in strategic planning. Regional Studies, 12(4), 463-479.

Cervero, R., \& Kockelman, K. (1997). Travel demand and the 3Ds: density diversity and design. Transportation Research Part D: Transport and Environment, 2, 199-219.

Curl, A., Nelson, J. D., \& Anable, J. (2011). Does accessibility planning address what matters? a review of current practice and practitioner perspectives. Research in Transportation Business \& Management, 2, 3-11.

Curtis, C., \& Scheurer, J. (2010). Planning for sustainable accessibility: developing tools to aid discussion and decision making. Progress in Planning, 74, 31-41.

Fotheringham, A. S., \& O’Kelly, M. E. (1989). Spatial interaction models: formulation and applications. Dordrecht: Kluwer Academic Press.

Geurs, K. T., \& van Wee, B. (2004). Accessibility evaluation of land-use and transport strategies: review and research directions. Journal of Transport Geography, 12, 127-140.

Geurs, K.T. \& Ritsema van Eck, J.R., (2001). "Accessibility measures: review and applications. Evaluation of accessibility impacts of land-use transportation scenarios, and related social and economic impact", RIVM Report 408505006 edn, National Institute of Public Health and the Environment, Bilthoven, Netherlands.

Goudie, D. (2002). Zonal method for urban travel surveys: sustainability and sample distance from the CBD. Journal of Transport Geography, 10, 287-301.

Gutierrez, J., \& Gomez, G. (1999). The impact of orbit motorways on intra-metropolitan accessibility: the case of Madrid's M-40. Journal of Transport Geography, 7, 1-15.

Hägerstrand, T. (1970). What about people in regional science? Papers in Regional Science, 4(1), 6-21.

Halden, D., McGuigan, D., Nisbet, A. \& McKinnon, A., (2000) "Accessibility: review of measuring techniques and their application", Scottish Executive

Halden, D., Jones, P., \& Wixey, S. (2005). Accessibility analysis literature review. London: University of Westminster.

Handy, S. (2002). Travel behaviour-land use interactions: an overview and assessment of the research. In H. S. Mahmassani (Ed.), Perpetual motion (pp. 223-236). Oxford: Pergamon Press.

Handy, S. L., \& Niemeier, D. A. (1997). Measuring accessibility: an exploration of issues and alternatives. Environment and Planning A, 29, 1175-1194.

Hansen, W. G. (1959). How accessibility shapes land use. Journal of the American Institute of Planners, 25(2), 73-76.

Hine, J., \& Mitchell, F. (2001). Better for everyone? travel experiences and transport exclusion. Urban Studies, 38(2), 319-332.

HSL. (2010). Liikkumistottumukset Helsingin seudun työssäkäyntialueella vuonna 2008. Helsinki: Edita Prima Oy.

HSL. (2013). Liikkumistottumukset Helsingin seudun työssäkäyntialueella vuonna 2013. Helsinki: Edita Prima Oy.

ICLEI, U., (2014) “Urban-LEDS”, Available: http://urbanleds.iclei.org/ [2014, 11/16].

Ingram, D. R. (1971). The concept of accessibility: a search for an operational form. Regional Studies, 5 , 101-107. 
Jaakkola, T., Tenkanen, H., Toivonen, T., (2015). "MetropAccess-Digiroad", in MetropAccess: Helsingin metropolialueen moniulotteista saavutettavuutta tutkimassa, Toivonen et al., eds., Helsingin yliopiston Geotieteiden ja maantieteen laitoksen julkaisuja C8.

Kawabata, M., \& Shen, Q. (2006). Job accessibility as an indicator of auto-oriented urban structure: a comparison of Boston and Los Angeles with Tokyo. Environment and Planning B: Planning and Design, 33(1), 115-130.

Kim, H.-M., \& Kwan, M.-P. (2003). Space-time accessibility measures: a geocomputational algorithm with a focus on the feasible opportunity set and possible activity duration. Journal of Geographical Systems, 5, $71-91$.

Koenig, J. G. (1980). Indicators of urban accessibility: theory and application. Transportation, 9(2), 145-172.

Kwan, M. P. (1998). Space-time and integral measures of individual accessibility: a comparative analysis using a point-based framework. Geographical Analysis, 30, 191-216.

Kwan, M., \& Weber, J. (2003). Individual accessibility revisited: Implications for geographical analysis in the twenty-first century. Geographical Analysis, 34(4), 341-353.

Kwan, M.-P., Murray, A. T., O’Kelly, M. E., \& Tiefelsdorf, M. (2003). Recent advances in accessibility research: representation methodology and applications. Journal of Geographical Systems, 5, 129-138.

Lei, T. L., \& Church, R. L. (2010). Mapping transit-based access: integrating GIS, routes and schedules. International Journal of Geographical Information Science, 24(2), 283-304.

LIPAS., (2013). Liikuntapaikat.fi [Homepage from the University of Jyväskylä], Available: http://lipas.cc.jyu. fi/lipas [2014, 04/07].

Lovett, A., Haynes, R., Sunnenberg, G., \& Gale, S. (2002). Car travel time and accessibility by bus to general practitioner services: a study using patient registers and GIS. Social Science \& Medicine, 55, 97-111.

Lucas, K. (2006). Providing transport for social inclusion within a framework for environmental justice in the UK. Transportation Research Part A: Policy and Practice, 40(10), 801-809.

Mavoa, S., Witten, K., McCreanor, T., \& O’Sullivan, D. (2012). GIS based destination accessibility via public transit and walking in Auckland, New Zealand. Journal of Transport Geography, 20(1), 15-22.

Miller, H. J. (1991). Modelling accessibility using space-time prism concepts within geographical information systems. International Journal of Geographical Information Systems, 5(3), 287-301.

Murray, A. T., \& Wu, X. (2003). Accessibility tradeoffs in public transi planning. Journal of Geographical Information Systems, 5(1), 93-107.

O’Sullivan, D., Morrison, A., \& Shearer, J. (2000). Using desktop GIS for the investigation of accessibility by public transport: an isochrone approach. International Journal of Geographical Information Science, 14, 85-104.

Páez, A., \& Scott, D. (2005). Spatial statistics for urban analysis: a review of techniques with examples. GeoJournal, 61(1), 53-67.

Páez, A., Scott, D. M., \& Morency, C. (2012). Measuring accessibility: positive and normative implementations of various accessibility indicators. Journal of Transport Geography, 25, 141-153.

Salonen, M., \& Toivonen, T. (2013). Modelling travel time in urban networks: comparable measures for private car and public transport. Journal of Transport Geography, 31, 143-153.

Salonen, M., Broberg, A., Kyttä, M., \& Toivonen, T. (2014). Do suburban residents prefer time-wise optimal or sustainable travel modes? combining public participation GIS and multimodal travel time analysis for daily mobility research. Applied Geography, 53, 438-448.

Service Map of Helsinki, Espoo, (2014). Vantaa and Kaunainen, Homepage of Helsinki City, Available: http:// www.hel.fi/palvelukartta (03/12).

Silva, C. (2008). "Comparative accessibility for mobility management. The structural accessibility layer", working paper, University of Oporto

Silva, C., \& Pinho, P. (2010). The Structural Accessibility Layer (SAL): revealing how urban structure constrains travel choice. Environment and Planning A, 42(11), 2735-2752.

Stanley, J., \& Vella-Brodrick, D. (2009). The usefulness of social exclusion to inform social policy in transport. Transport Policy, 16(3), 90-96.

Statistics Finland. (2012). "Population in 250 meter grid squares", in Ruutuaineistot yhdyskuntarakenteen seurantaj'rjestelm'ss' (YKR) data set.

Tillema, T., Van Wee, B. \& Tom De, J. (2003). "Road pricing from a geographical perspective: A literature review and implications for research into accessibility", European Regional Science Association, 43rd ERSA Congress, August 27-30.

Van Wee, B., Hagoort, M., \& Annema, J. A. (2001). Accessibility measures with competition. Journal of Transport Geography, 9(3), 199-208.

Vickerman, R. W. (1974). Accessibility attraction, and potential: a review of some concepts and their for determining mobility. Environment and Planning A, 6, 675-691. 
Vlek, C. \& Steg, L. (1996). "Societal reasons, conditions and policy strategies for reducing the use of motor vehicles", in Towards sustainable transportation, Vancouver, Canada, March 24-27.

Wachs, M. (1978). Accessibility, Mobility and Travel Need, Croom Helm, London.

Wegener, M. \& Fürst, F. (1999). Land-Use Transport Interaction: State of the Art, Institut für Raumplanung, Dortmund.

Williams, P.A. \& Fotheringham, A. S. (1984). The calibration of spatial interaction models by maximum likelihood estimation with program SIMODEL, Geographic Monograph Series, vol. 7, Department of Geography, Indiana University

Wilson, A. G. (1967). A statistical theory of spatial distribution models. Transportation Research, 1, $253-269$.

Wilson, A. G. (1971). A family of spatial interaction models and associated developments. Environment and Planning, 1, 1-32.

Yigitcanlar, T., Sipe, N. G., Evans, R., \& Pitot, M. (2007). A GIS-based land use and public transport accessibility indexing model. Australian Planner, 44(3), 30-37. 